\title{
Axillary Recurrences after Sentinel Node Surgery-Results over Ten Years in a University Hospital
}

\author{
Helle Eilertsen ${ }^{1}$, Ellen Schlichting ${ }^{2}$, Marianne Efskind Harr ${ }^{3}$, Daehoon Park ${ }^{4}$, Torill Sauer ${ }^{1,5}$, \\ Siri Larønningen ${ }^{6}$, Rolf Kaaresen ${ }^{1,2^{*}}$
}

${ }^{1}$ Medical Faculty, University of Oslo, Oslo, Norway; ${ }^{2}$ Department of Breast and Endocrine Surgery, Oslo University Hospital, Oslo, Norway; ${ }^{3}$ Department of Neurosurgery, Oslo University Hospital, Oslo, Norway; ${ }^{4}$ Department of Pathology, Vestre Viken Hospital, Drammen, Norway; ${ }^{5}$ Department of Pathology, Oslo University Hospital, Oslo, Norway; ${ }^{6}$ Cancer Registry of Norway, Oslo, Norway. Email: * rolf.karesen@medisin.uio.no

Received July 10 $0^{\text {th }}$,2012; revised August $15^{\text {th }}, 2012$; accepted August $27^{\text {th }}, 2012$

\begin{abstract}
Background: Sentinel node biopsy (SNB) was introduced at Ullevaal University Hospital in 2000. This article presents results from the first ten years use of the method. Material and Methods: A prospective registration of 2762 patients was made from 2000 through 2009. Results: The median follow-up time was 51 months. The overall detection rate was 93\%. 36\% of the patients with positive SNs had non-sentinel metastases. These were significantly associated with a macrometastatic SN and a primary tumour $>20 \mathrm{~mm} .18 \%$ of patients with sentinel metastasis $\leq 2 \mathrm{~mm}$ had non-sentinel metastases. 14 patients with negative SN $(0.7 \%)$ developed axillary recurrence. $32 \%$ with a preoperative diagnosis of ductal carcinoma in situ (DCIS) were upstaged to infiltrating carcinoma on final histology. None of the patients with pure DCIS had positive SNs. Conclusion: Few late events $(0.7 \%)$ in SN negative axillas demonstrate the safety of the technique.
\end{abstract}

Keywords: Breast Cancer; Ductal Carcinoma in Situ; Sentinel Node; Non-Sentinel Metastasis; Axillary Recurrence

\section{Introduction}

As one of the first hospitals in Norway, Ullevaal University Hospital introduced sentinel node biopsy (SNB) as a routine method in March 2000.

Between 400 and 500 patients were diagnosed with breast cancer in the hospital per year during the study period.

We present the results from the first ten years using the SNB technique with a particular focus on three aspects:

- Axillary recurrences in patients with negative SN in the first operation;

- The correlation between size of SN metastasis and the risk of metastasizing to non-SN lymph nodes;

- The role of SN biopsy in patients with a preoperative diagnosis of ductal carcinoma in situ (DCIS).

\section{Patients and Methods}

Between March 2000 and December 2009, 2762 patients (2751 women and 11 men) with breast cancer underwent SNB at Ullevaal University Hospital. 36 patients had bilateral surgery and thus 2798 SNBs were performed during the study period. The median age was 58 years (22 - 92). 85\% of the patients had preoperative diagnosis

\footnotetext{
${ }^{*}$ Corresponding author.
}

of DCIS or infiltrating carcinoma by either fine needle aspiration cytology (FNAC) or core biopsy, the rest by surgical biopsy.

\subsection{Registration of Data}

A prospective, scheme based registration was used. The data was kept in an internal hospital database with the acceptance from the relevant authorities.

\subsection{Inclusion and Exclusion Criteria}

For the first 5 years patients $\leq 75$ year with a preoperatively estimated tumour size $\leq 3 \mathrm{~cm}$ were included. The last 5 years also patients with tumours between 3 and 5 $\mathrm{cm}$ were included with no upper age limit.

The exclusion criteria for the entire period were patients with cytologically verified axillary metastases and those who had preoperative chemotherapy. During the first 5 years DCIS and multifocal disease were exclusion criteria, but for the last 5 years multifocality and DCIS grade III on cytology or histology were included.

\subsection{Identification of the Sentinel Node}

Both blue dye and radioactivity were used to identify the 
SN. For the first 6 years, blue dye (One ml patent blue diluted to $5 \mathrm{ml}$ with isotone saline) and radioactivity (80 $\mathrm{mBq}$ in $08 \mathrm{ml}$ ) were injected peritumourally. From January 2006 the injection was made periareolarly. Radioactivity was injected the day before surgery, whereas blue dye was injected after the patients were under general anaesthesia.

A lymph node was defined as a SN if the radioactivity was at least ten times the background activity, whereas the degree of colour was determined by a subjective assessment by the surgeon.

\subsection{Histopathological Examination of Sentinel Node}

All sentinel nodes were intraoperatively sent to frozen section examination. The nodes were bisected along the longitudinal axis and $2-3$ frozen sections were cut from each cut surface. About $8-12$ sections were examined per lymph node. All SNs were later formalin fixated, paraffin embedded and stained with hematoxylin-eosin and examined as part of the final histological evaluation. (Figure 1) In cases of doubt, immunohistochemical testing was performed [1].

\subsection{Axillary Lymph Node Dissection}

Axillary lymph node dissection (ALND) was performed if the SN was positive either intraoperatively or after final histological assessment. In the case of a negative SN intraoperatively, the patient was reoperated if final histology found a metastasis. Patients found to have SNs with isolated tumour cells (metastasis $<0.2 \mathrm{~mm}$ ) did not undergo ALND, according to the guidelines of the Norwegian Breast Cancer Group (NBCG) [2].

\subsection{Reevaluation of Positive SNs}

Positive SNs were later re-examined and the largest diameter of metastasis remeasured by an independent pa-

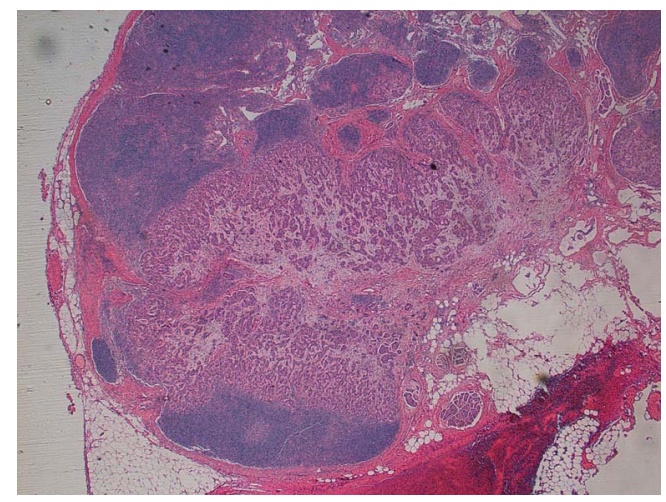

Figure 1. Hematoxylin and eosin stained sentinel node with metastasis from an infiltrating ductal carcinoma, micro papilary subtype. thologist (DP) blinded for other data.

\subsection{Definition of Axillary Recurrence}

Axillary recurrence was defined as detection of cancer cells in the axilla more than 120 days after the date of primary axillary surgery. The reports of axillary recurrences were found by searching the patient records in the hospital verified and supplemented by the Cancer Registry of Norway.

\subsection{Statistical Analysis}

Comparison of data between groups was made using chisquare test and Fisher exact test. Multivariable analyses were made using a multiple logistic regression model. A two-tailed p-value of 0.05 or less was considered statistically significant. Analyses were performed using SPSS version 18.0 (SPSS Inc., Chicago, Illinois, USA).

\section{Results}

Median follow-up time was 51 months $(0$ - 117). Histopathological tumour characteristics are given in Table 1.

\subsection{Detection of Sentinel Node}

The detection rate for the entire period was 93\% (95\% CI 92 - 94). Peritumoural injection of blue dye and radioactivity gave a detection rate of $90 \%(95 \%$ CI $88-91)$, whereas the detection rate with periareolar injection was $96 \%$ (95\% CI 95 - 97). There was a significant difference in detection rate after change of injection site $(\mathrm{p}<0.001)$.

A total of 30 surgeons did the SN procedures. Their detection rate did not differ significantly when grouped according to the number of procedures they performed (Table 2).

On multivariable analysis, neither age, tumour grade or tumour size was found to be significant factors in the detection of SN.

A median value of 1 node [1-8] was retrieved during the SNB.

$27 \%$ of the patients in whom SN was not found, had a metastasis to one or more axillary nodes. The median value of metastatic nodes after ALND was 3 (range 1 $15)$.

\subsection{Positive Sentinel Nodes}

A positive SN on final histopathological examination was found in $620(24 \%)$ of the 2586 patients where SN was detected. The largest diameter of SN metastases in each patient categorized in three groups is shown in Table 3.

141 patients had an intraoperatively false negative SN and were reoperated with ALND. The negative predicttive value of intraoperative SN assessment was $93 \%$ 
Table 1. Tumour characteristics of 2798 breast cancer patients. Missing data given in numbers only. The percentages show the distribution of the parameters in known cases.

\begin{tabular}{|c|c|c|}
\hline $\begin{array}{l}\text { Median invasive tumour size } \\
\quad(\mathrm{n}=2476, \text { missing } 41)\end{array}$ & & $15 \mathrm{~mm}$ (range $0.5-86$ ) \\
\hline \multicolumn{3}{|l|}{ Histological type $(\mathrm{n}=2776)$} \\
\hline & Ductal & $1507(54 \%)$ \\
\hline & Lobular & $220(8 \%)$ \\
\hline & DCIS & $246(9 \%)$ \\
\hline & Ductal + DCIS & $623(22 \%)$ \\
\hline & Other & $180(7 \%)$ \\
\hline & Missing & 22 \\
\hline \multicolumn{3}{|l|}{$\begin{array}{l}\text { Histological grading of } \\
\text { invasive ductal carcinomas } \\
(\mathrm{n}=1499)\end{array}$} \\
\hline & 1 & $469(31 \%)$ \\
\hline & 2 & $695(47 \%)$ \\
\hline & 3 & $335(22 \%)$ \\
\hline & Missing & 8 \\
\hline \multicolumn{3}{|l|}{$\begin{array}{l}\text { Oestrogen receptor status: } \\
\qquad(\mathrm{n}=2456)\end{array}$} \\
\hline & Positive & $2059(84 \%)$ \\
\hline & Negative & $397(16 \%)$ \\
\hline & Missing & 61 \\
\hline \multicolumn{3}{|l|}{$\begin{array}{l}\text { Progesterone receptor status } \\
\qquad(\mathrm{n}=2444)\end{array}$} \\
\hline & Positive & $1662(68 \%)$ \\
\hline & Negative & $782(32 \%)$ \\
\hline & Missing & 73 \\
\hline \multicolumn{3}{|l|}{ Her2 status $\left(\mathrm{n}=1459^{*}\right)$} \\
\hline & Positive & $138(9 \%)$ \\
\hline & Negative & $1321(91 \%)$ \\
\hline & Missing & 39 \\
\hline
\end{tabular}

"The registration of Her2 started in 2004.

Table 2. Detection rate related to total number of sentinel node (SN) procedures done by each surgeon.

\begin{tabular}{ccccc}
\hline $\begin{array}{c}\text { Total SN } \\
\text { procedures per } \\
\text { surgeon }\end{array}$ & $\leq 30$ & $>30 \leq 100$ & $>100 \leq 400$ & $>400$ \\
\hline $\begin{array}{c}\text { Det. Rate } \\
{[95 \% \mathrm{CI}]}\end{array}$ & $\begin{array}{c}91 \% \\
{[86-95]}\end{array}$ & $\begin{array}{c}94 \% \\
{[91-97]}\end{array}$ & $\begin{array}{c}92 \% \\
{[91-94]}\end{array}$ & $\begin{array}{c}93 \% \\
{[91-94]}\end{array}$ \\
\hline
\end{tabular}

(95\% CI 92 - 94). Of the patients with an intraoperatively false negative SN, $71 \%$ had micrometastasis $\leq 2 \mathrm{~mm}$.

On multivariable analysis, tumour size $>20 \mathrm{~mm}$ had a significant association to positive sentinel nodes $(\mathrm{p}<$ 0.001 ), whereas tumour grade and receptor status had no significant correlation.

\subsection{Non-SN Metastases in Patients with Positive SN}

Of the patients with positive SN, 36\% had metastasized also to non-sentinel lymph nodes.

There was a significant difference in the share of non-SN metastases in correlation with size of the SN metastasis $(\mathrm{p}<0.001)$ (Table 4).

A multivariable analysis comparing SN positive patients with and without non-sentinel metastasis, found that the only other characteristic, apart from size of SN metastasis, was size of primary tumour. A significant difference was seen between patients with tumours smaller than and larger than $20 \mathrm{~mm}(\mathrm{p}=0.013)$.

\subsection{Positive Sentinel Node in Ductal Carcinoma in Situ Grade III}

There were 225 patients with DCIS grade III on either FNAC or core biopsy. Of these, 72 (32\%) had infiltrating carcinoma on final histology. Of the 211 patients with a preoperative DCIS grade III diagnosis that we have data on, 23 had a positive SN (11\%), 11 of which had micrometastasis $\leq 2 \mathrm{~mm}$. None of the patients with DCIS on final histology had a positive SN.

\subsection{Axillary Recurrences in SN Negative Patients}

Of those with negative $\mathrm{SN}$, axillary recurrence was seen in 14 patients $(0.7 \%)$. The median interval of months between time of surgery and registered date of axillary recurrence was 24 (range 4 - 34).

A comparison of tumour characteristics of patients with and without axillary recurrences, showed significant differences for grade 3 tumours $(p=0.012)$, but not for age, size or receptor status (Table 5).

Ki67 expression was seen in $92 \%$ of the patients with axillary recurrence.

Table 3. Largest diameter of sentinel node (SN) metastases.

\begin{tabular}{cccc}
\hline Size & $\leq 2 \mathrm{~mm}$ & $>2 \leq 5 \mathrm{~mm}$ & $>5 \mathrm{~mm}$ \\
\hline $\begin{array}{c}\text { Share of SN metastases } \\
(\mathrm{n}=620,16 \text { missing })\end{array}$ & $170(28 \%)$ & $158(26 \%)$ & $276(46 \%)$ \\
\hline
\end{tabular}

Table 4. Share of non-sentinel node (SN) metastasis related to size of sentinel node metastasis.

\begin{tabular}{cccc}
\hline Size $(\mathrm{mm})$ & $\leq 2$ & $>2 \leq 5$ & $>5$ \\
\hline $\begin{array}{c}\text { Non-SN metastasis } \\
{[95 \% \mathrm{CI}]}\end{array}$ & $17 \%[12-23]$ & $33 \%[26-40]$ & $49 \%[43-55]$ \\
\hline
\end{tabular}


Table 5. Tumour characteristics in patients with and without axillary recurrence.

\begin{tabular}{cccc}
\hline & $\begin{array}{c}\text { Patients with } \\
\text { negative SN, } \\
\mathrm{n}=1966\end{array}$ & $\begin{array}{c}\text { Patients with axil- } \\
\text { lary recurrence, } \\
\mathrm{n}=14\end{array}$ & $\mathrm{p}$-value \\
\hline $\begin{array}{c}\text { Median age } \\
\text { (years) } \\
\text { Grade 3 }\end{array}$ & 59 & 14 & $\mathrm{NS}^{*}$ \\
$\begin{array}{c}\text { Oestrogen receptor } \\
\text { negative } \\
\text { Progesteron } \\
\text { receptor negative } \\
\text { Median invasive } \\
\text { tumour size (mm) }\end{array}$ & $544 / 1661(33 \%)$ & $6 / 12(50 \%)$ & $\mathrm{NS}^{*}$ \\
\hline
\end{tabular}

*NS: Non significant.

\section{Discussion}

Our rate of axillary recurrences supports the conclusion from other studies: A negative $\mathrm{SN}$ is a reliable indicator of axillary status and omitting axillary dissection after negative sentinel node biopsy is safe [9-14].

\subsection{Detection Rate}

Our overall detection rate is slightly lower than what is reported in other studies [3-6], but meets the requirements set by NBCG. The significant difference in detection rate after change of injection site support the change in guidelines made by NBCG [2] from peritumoral to periareolar injection as the preferred method. As we found no significant differences in identification rate between the experienced and inexperienced surgeons, a hypothesis that the detection rate was so low because of a large number of inexperienced surgeons at our teaching hospital failed. Further, no clinical or tumour characteristics were found to be significant in detecting SN. This suggests that the method is less dependent of the surgeon and the patient population and more dependent on qualities within the method itself. An explanation for the relatively low detection rate might be our stringent definition for a $\mathrm{SN}$ to have at least ten times the background radioactivity. Most publications on the method does not define this level and might have included nodes we excluded due to too low levels of activity.

\subsection{Non-Sentinel Node Metastases}

Macrometastasis to $\mathrm{SN}$ and size of primary tumour are significant predictors for the involvement of non-SN metastasis. Similar findings have been reported in other studies $[6-8,15,16]$.

$18 \%$ of our patients with a $\mathrm{SN}$ metastasis $\leq 2 \mathrm{~mm}$ had further nodal involvement. A metaanalysis of 25 studies found an incidence of further nodal involvement in $20 \%$ of patients with micrometastasis or isolated tumour cells to SN [17]. The literature has for years been contradicttory about micrometastases influence on recurrence and survival $[7,9,18]$. Guiliano et al. recently concluded in their randomized controlled trial that ALND might no longer be justified for women with small breast carcinomas and a positive SN as long as a set of specified adjuvant therapies are given [19]. The Norwegian Breast Cancer Group have decided that patients with SN metastasis $\leq 2 \mathrm{~mm}$ should avoid having ALND if breast preserving therapy including radiotherapy to the breast and lower axilla is carried out [2]. Similar to Hulvat et al. [20], we did not find any correlation between receptor positivity and/or histology grade with either SN or nonSN metastasis.

\subsection{Sentinel Node Metastasis in Ductal Carcinoma in Situ}

The value of doing SNB in DCIS has been disputed; some authors are in favour $[10,11,21,22]$, others against [9-11,15-19,21-25]. Most, however, agree that it should be done in patients who undergo mastectomy, because this eradicates the possibility to later perform SNB if preoperative diagnosis of DCIS is changed to infiltrating carcinoma [26-28].

None of the preoperative DCIS patients in our material, who on final histology was found to have true DCIS had positive SNs, whereas $11 \%$ of the patients that were upstaged to infiltrating carcinoma did. Based on these results we find that omitting SNB in patients with pure DCIS on final histology could be justified, whereas patients that on final histology have an infiltrating component should undergo SNB. The large share of patients in our material (32\%) who were upstaged from a preoperative diagnosis of DCIS grade III by FNAC or core biopsy to infiltrating carcinoma on final histology, shows that invasive foci are often overseen in the preoperative evaluation.

Some studies [10,29,30] have looked at risk factors among preoperative DCIS patients that can predict presence of an invasive component and thus who could benefit from having SNB performed as part of the initial operation. These studies have contradicting results and a definite conclusion is thus not possible.

\subsection{Axillary Recurrences}

An axillary recurrence rate of $0.7 \%$ with a median follow up time of 51 months is acceptable and in accordance with the results from other studies. A recent study with a median follow-up time similar to ours, found a recurrence rate of $0.7 \%$ [31], another reports an axillary recurrence rate of $0.6 \%$ after a median follow up time of 37 months [32]. A systematic review and meta-analysis of 
48 studies found a recurrence rate for axillary metastasis in clinically node negative women with a primary negative SN of $0.3 \%$ after a median follow up time of 34 months [33].

Our results indicate that longer follow-up time does not increase the rate of recurrence much, in accordance with other studies which observe that the majority of recurrences happens during the first two years after diagnosis [5,19,34].

Apart from a significant higher share of grade 3 tumours, we found no other significant characteristics in the axillary recurrence population. Similar results were reported by Kiluk et al. [35] and Bergquist et al. [32]. However, we had very few cases of recurrences in each risk category, and the lack of significant relation of recurrence to the other risk factors may be due to the low number $(n=14)$ and thus lack of statistical power.

One explanation of the low axillary recurrence rate might be that we have a low-risk population with a high percentage of good prognostic factors such as small tumour size (median $15 \mathrm{~mm}$ ), oestrogen $(84 \%)$ and progesterone $(68 \%)$ positivity and a low frequency of poor prognostic factors, such as lymph node involvement (24\%) and Her2 positivity (9\%) (Table 1). This selection is probably explained by the introduction of mammography screening for women aged 50 - 69 in the hospital's referral area in 1996, four years prior to the introduction of the $\mathrm{SN}$ procedure.

\section{Conclusions}

Few recurrences $(0.7 \%)$ in $\mathrm{SN}$ negative axillas demonstrate the safety of the technique. Apart from a significant higher share of grade 3 tumours, we found no other significant characteristics in the axillary recurrence population. The median time to recurrence was 24 months.

The rather high frequency of patients with non-SN metastases, also in those with micrometastasis (18\%), shows that removal of SN alone might not be sufficient for local control of the axilla if axillary x-ray treatment is not included.

The SN procedure seems unnecessary in patients with histology proven DCIS not undergoing mastectomy.

\section{Acknowledgements}

Assistance with the finding and verification of recurrences by Ann Helen Seglem and Monica Johansen, Cancer Registry of Norway is acknowledged.

\section{REFERENCES}

[1] T. Sauer, V. Engh, A. M. Holck, G. Sørpebøl G. M. Heim, I. Furu and E. Schlichting, "Imprint Cytology of Sentinel Lymph Nodes in Breast Cancer," Acta Cytologica, Vol.

\section{7, No. 5, 2003, pp. 768-773. doi:10.1159/000326603}

[2] Norwegian Breast Cancer Group Guidelines. www.nbcg.no

[3] U. Veronesi, G. Paganelli, G. Viale, A. Galimberti, A. Luini, S. Zurrida et al., "Sentinel Lymph Node Biopsy and Axillary Dissection in Breast Cancer: Results in a Large Series," Journal of the National Cancer Institute, Vol. 91, No. 4, 1999, pp. 368-373. doi:10.1093/jnci/91.4.368

[4] T. Kim, A. E. Giuliano and G. H. Lyman, "Lymphatic Mapping and Sentinel Lymph Node Biopsy in EarlyStage Breast Carcinoma: A Metaanalysis," Cancer, Vol. 106, No. 1, 2006, pp. 4-16. doi:10.1002/cncr.21568

[5] M. L. Smidt, C. M. M Janssen, D. M. Kuster, E. D. M. Bruggink and L. J. A. Strobbe. "Axillary Recurrence after a Negative Sentinel Node Biopsy for Breast Cancer: Incidence and Clinical Significance," Annals of Surgical Oncology, Vol. 12, No. 1, 2005, pp. 29-33. doi:10.1007/s10434-004-1166-0

[6] M. E. Straver, P. Meijnen, G. van Tienhoven, C. J. H. van de Velde, R. E. Mansel, J. Bogaerts, et al., "Sentinel Node Identification Rate and Nodal Involvement in the EORTC 10981-22023 AMAROS Trial," Annals of Surgical Oncology, Vol. 17, No. 7, 2010, pp. 1854-1861. doi:10.1245/s10434-010-0945-Z

[7] K. U. Chu, R. R Turner, N. M. Hansen, M. B. Brennan and A. E. Giuliano, "Sentinel Node Metastasis in Patients with Breast Carcinoma Accurately Predicts Immunohistochemically Detectable Nonsentinel Node Metastasis," Annals of Surgical Oncology, Vol. 6, No. 8, 1999, pp. 756-761. doi:10.1007/s10434-999-0756-2

[8] G. Peclivanides, D. Vassilaros, A. Tsimpanis, A. Apostolopoulou and S. Vasilaros, "Sentinel Node Biopsy for Breast Cancer Patients: Issues for Discussion and Our Practice," Pathology Research International, Vol. 201, 2011, 8 Pages, Article ID: 109712. doi: $10.4061 / 2011 / 109712$

[9] U. Veronesi, G. Paganelli, G. Viale, A. Luini, S. Zurrida, V. Galimberti, et al., "A Randomized Comparison of Sentinel-Node Biopsy with Routine Axillary Dissection in Breast Cancer," The New England Journal of Medicine, Vol. 349, 2003, pp. 546-553. doi:10.1056/NEJMoa012782

[10] C. E. Cox, K. Ngyen, R. J. Gray, C. Salud, N. N. Ku, E. Dupont, et al., "Importance of Lymphatic Mapping in Ductal Carcinoma in Situ (DCIS): Why Map DCIS?" The American Surgeon, Vol. 67, No. 6, 2001, pp. 213-221.

[11] B. Doyle, M. Al-Mudhaffer, M. M. Kennedy, A. O'Doherty, F. Flanagan, E. W. McDermott, et al., "Sentinel Lymph Node Biopsy in Patients with a Needle Core Biopsy Diagnosis of Ductal Carcinoma in Situ: Is It Justified?" Journal of Clinical Pathology, Vol. 62, No. 6, 2009, pp. 534-538. doi:10.1136/jcp.2008.061457

[12] U. Veronesi, G. Viale, G. Paganelli, S. Zurrida, A. Luini, V. Galimbert, et al., "Sentinel Lymph Node Biopsy in Breast Cancer: Ten-Year Results of a Randomized Controlled Study," Annals of Surgery, Vol. 251, No. 4, 2010, pp. 595-600. doi:10.1097/SLA.0b013e3181c0e92a

[13] D. N. Krag, S. J. Anderson, T. B. Julian, A. M. Brown, S. 
P. Harlow, J. P. Constantino, et al., "Sentinel-LymphNode Resection Compared with Conventional AxillaryLymph-Node Dissection in Clinically Node-Negative Patients with Breast Cancer: Overall Survival Findings from the NSABP B-32 Randomised Phase 3 Trial," The Lancet Oncology, Vol. 11, No. 10, 2010, pp. 927-933. doi:10.1016/S1470-2045(10)70207-2

[14] P. Poletti, P. Fenaroli, A. Milesi, S. Mangiarotti, G. Virotta, E. Candiago, et al., "Axillary Recurrence in Sentinel Lymph Node-Negative Breast Cancer Patients," Annals of Oncology, Vol. 19, No. 11, 2008, pp. 1842-1846. doi:10.1093/annonc/mdn393

[15] F. J. Fleming, D. Kavanagh, T. B. Crotty, C. M. Quinn, C. M. McDermott, N. O'Higgins and A. D. K. Hill, "Factors Affecting Metastases to Non-Sentinel Lymph Nodes in Breast Cancer," Journal of Clinical Pathology, Vol. 57, No. 1, 2004, pp. 73-76. doi:10.1136/jcp.57.1.73

[16] U. Sachdev, K. Murphy, A. Derzie, S. Jaffer, I. J. Bleiweiss and S. Brower, "Predictors of Nonsentinel Lymph Node Metastasis in Breast Cancer Patients," The American Journal of Surgery, Vol. 183, No. 3, 2002, pp. 213-217. doi:10.1016/S0002-9610(02)00794-8

[17] G. Cserni, D. Gregori, F. Merletti, A. Sapino, M. P. Mano, A. Ponti, et al., "Meta-Analysis of Non-Sentinel Node Metastases Associated with Micrometastatic Sentinel Node in Breast Cancer," British Journal of Surgery, Vol. 91, No. 10, 2004, pp. 1245-1252. doi:10.1002/bjs.4725

[18] N. Wasif, M. A. Maggard, C. Y. Ko and A. E. Giuliano, "Underuse of Axillary Dissection for the Management of Sentinel Node Micrometastases in Breast Cancer," Archives of Surgery, Vol. 145, No. 2, 2010, pp. 161-166.

[19] A. E. Giuliano, K. K. Hunt, K.V . Ballman, P. D. Beitsch, P. W. Whitworth, P. W. Blumencranz, et al., "Axillary Dissection vs No Axillary Dissection in Women with Incasive Breast Cancer and Sentinel Node Metastasis-A Randomized Clinical Trial," The Journal of the American Medical Association, Vol. 305, No. 6, 2011, pp. 569-575. doi:10.1001/jama.2011.90

[20] M. Hulvat, P. Rajan, E. Rajan, S. Sarker, C. Schermer, G. Aranhana and K.Yao, "Histopathologic Characteristics of the Primary Tumor in Breast Cancer Patients with Isolated Tumor Cells of the Sentinel Node," Surgery, Vol. 144, No. 4, 2008, pp 518-524. doi:10.1016/j.surg.2008.06.006

[21] J. S. Han, K. H. Molberg and V. Sarode. "Predictors of Invasion and Axillary Lymph Node Metastasis in Patients with a Core Biopsy Diagnosis of Ductal Carcinoma in Situ: An Analysis of 255 Cases," The Breast Journal, Vol. 17, No. 3, 2009, pp. 223-229. doi:10.1111/j.1524-4741.2011.01069.x

[22] B. Ansari, S. A. Ogston, C. A. Purdie, D. J. Adamson, D. C. Brown and A. M. Thompson, "Meta-Analysis of Sentinel Node Biopsy in Ductal Carcinoma in Situ of the Breast," British Journal of Surgery, Vol. 95, No. 5, 2008, pp. 547-554. doi:10.1002/bjs.6162

[23] K. Tada, A. Ogiya, K. Kimura, H. Morizono, K. Iijima, Y. Miyagi, et al., "Ductal Carcinoma in Situ and Sentinel Lymph Node Metastasis in Breast Cancer," World Journal of Surgical Oncology, Vol. 8, No. 6, 2010, 5 Pages. doi:10.1186/1477-7819-8-6

[24] G. Zavagno, P. Carcofor, R. Marconato, Z. Franchini, G. Scalco, P. Burelli, et al., "Role of Axillary Sentinel Lymph Node Biopsy in Patients with Pure Ductal Carcinoma in Situ of the Breast," BMC Cancer, Vol. 5, No. 28, 2005, 6 Pages. doi:10.1186/1471-2407-5-28

[25] M. Intra, N. Rotmensz, P. Veronesi, M. Colleoni, S. Iodice, G. Paganelli, et al., "Sentinel Node Biopsy Is Not a Standard Procedure in Ductal Carcinoma in Situ of the Breast: Experience of the European Institute of Oncology on 854 Patients in 10 Years," Annals of Surgery, Vol. 247, No. 2, 2008, pp. 315-319. doi:10.1097/SLA.0b013e31815b446b

[26] C. Schneider, S. Trocha, B. McKinley, J. Shaw, S. Bielby, D. Blackhurst, et al., "The Use of Sentinel Lymph Node Biopsy in Ductal Carcinoma in Situ," The American Surgeon, Vol. 76, No. 9, 2010, pp. 943-946.

[27] A. Goyal, A. Douglas-Jones, I. Monypenny, H. Sweetland, G. Stevens and R. E. Mansel, "Is There a Role of Sentinel Lymph Node Biopsy in Ductal Carcinoma in Situ?: Analysis of 587 Cases," Breast Cancer Research and Treatment, Vol. 98, No. 3, 2006, pp. 311-314.

[28] T. Takács, A. Paszt, K. Szentpáli, K. Ormándi, M- L. I. Pálka, et al., "Importance of Sentinel Lymph Node Biopsy in Surgical Therapy of in Situ Breast Cancer," Pathology \& Oncology Research, Vol. 15, No. 3, 2009, pp. 329-333. doi:10.1007/s12253-008-9123-Z

[29] E. D. Kurniawan, A. Rose, A. Mou, M. Buchanan, J. P. Collins, M. H. Wong, et al., "Risk Factors for Invasive Breast Cancer When Core Needle Biopsy Shows Ductal Carcinoma in Situ," Archives of Surgery, Vol. 145, No. 11, 2010, pp. 1098-1104. doi:10.1001/archsurg.2010.243

[30] M. E. Brennan, R. M. Turner, S. Ciatto, M. L. Marinovich, J. R. French, P. Macaskill and N. Houssami, "Ductal Carcinoma in Situ at Core-Needle Biopsy: MetaAnalysis of Underestimation and Predictors of Invasive Breast Cancer," Radiology, Vol. 260, No. 1, 2011, pp. 119128. doi:10.1148/radiol.11102368

[31] C. Dauphine, D. Nemtsev, D. Rosing and H. I. Vargas, "Axillary Recurrence after Sentinel Lymph Node Biopsy for Breast Cancer," The American Surgeon, Vol. 76, No. 10, 2010, pp. 1127-1129.

[32] L. Bergquist, J. de Boniface, P.-E. Jönsson, C. Ingvar, G. Liljegren and J. Frisell, "Axillary Recurrence Rate after Negative Sentinel Node Biopsy in Breast Cancer," Annals of Surgery, Vol. 247, No. 1, 2008, pp. 150-156. doi:10.1097/SLA.0b013e318153ff40

[33] I. M. van der Ploeg, O. E. Nieweg, M. C. van Rijk, R. A. Valdés Olmos and B. B. Kroon, "Axillary Recurrence after a Tumour-Negative Sentinel Node Biopsy in Breast Cancer Patients: A Systematic Review and Meta-Analysis of the Literature," European Journal of Surgical Oncology, Vol. 34, No. 12, 2008, pp. 1277-1284. doi:10.1016/j.ejso.2008.01.034

[34] M. Greco, R. Agresti, N. Cascinelli, P. Casalini, R. Giovanazzi, A. Maucione, et al., "Breast Cancer Patients Treated without Axillary Surgery: Clinical Implications and Biologic Analysis," Annals of Surgery, Vol. 232, No. 1, 2000, pp. 1-7. 
doi:10.1097/00000658-200007000-00001

[35] J. V. Kiluk, Q. P. Ly, A. A. Santillan, T. Meade, D. Ramos, D. S. Reintgen, et al., "Erratum to: Axillary Recurrence Rate Following Negative Sentinel Node Biopsy for Invasive Breast Cancer: Long-Term Follow-Up," Annals of Surgical Oncology, Vol. 17, No. 2, 2010, pp. 552557. doi:10.1245/s10434-009-0800-2 